\title{
Transcriptional Control of Inflammatory Responses
}

\author{
Stephen T. Smale ${ }^{1}$ and Gioacchino Natoli ${ }^{2}$ \\ ${ }^{1}$ Department of Microbiology, Immunology, and Molecular Genetics, University of California, Los Angeles, \\ California 90095 \\ ${ }^{2}$ Department of Experimental Oncology, European Institute of Oncology (IEO), I-20139 Milan, Italy \\ Correspondence: gioacchino.natoli@ieo.eu
}

The inflammatory response requires the activation of a complex transcriptional program that is both cell-type- and stimulus-specific and involves the dynamic regulation of hundreds of genes. In the context of an inflamed tissue, extensive changes in gene expression occur in both parenchymal cells and infiltrating cells of the immune system. Recently, basic transcriptional mechanisms that control inflammation have been clarified at a genome scale, particularly in macrophages and conventional dendritic cells. The regulatory logic of distinct groups of inflammatory genes can be explained to some extent by identifiable sequenceencoded features of their chromatin organization, which impact on transcription factor (TF) accessibility and impose different requirements for gene activation. Moreover, it has become apparent that the interplay between TFs activated by inflammatory stimuli and master regulators exerts a crucial role in controlling cell-type-specific transcriptional outputs.

Survival of any living organism, from simple Prokaryotes to complex multicellular eukaryotes, critically relies on its ability to sense virtually every environmental change and to mount highly specialized responses that are tailored on both the precise nature of the stimulus and its intensity. Among environmental responses, inflammation is especially complex as a consequence of several factors: (1) its essential role as a first line of defense against microbes, as a source of instructions to the adaptive immune system, and as the starting point for resolution and repair; (2) the enormous variety of potentially dangerous microbes and their extreme ability to evolve under the pressure of the host immune system; and (3) finally, the exten- sive exploitation of molecules and mechanisms invented in evolution for antimicrobial defense and to solve nonmicrobial tissue damage.

At the cellular level, the very basis of inflammation is the deployment of complex gene expression programs that include hundreds of genes and are activated within minutes after the primary stimulus (Medzhitov and Horng 2009). Although these programs include a core set of genes that are almost invariably activated in most cell types and in response to most inflammatory stimuli, they extensively differ from each other depending on the cell type and tissue in which they are elicited, the nature and the intensity of the trigger, as well as the preexisting cellular or organismal conditions (Smale 2010).

Editor: Ruslan M. Medzhitov

Additional Perspectives on Innate Immunity and Inflammation available at www.cshperspectives.org

Copyright (C) 2014 Cold Spring Harbor Laboratory Press; all rights reserved; doi: 10.1101/cshperspect.a016261

Cite this article as Cold Spring Harb Perspect Biol 2014;6:a016261 
For instance, in distinct cell types, a specific inflammatory stimulus can activate the same set of transcription factors (TFs) and yet produce different transcriptional responses. As explained below, this occurs because each cell type has a unique repertoire of available genomic transcriptional regulatory elements that have been specified during its differentiation, and, thus, differ from those of any other differentiated cell type (Natoli 2010). Moreover, the same cell type (e.g., a macrophage) can be differentially conditioned by the tissue milieu to the point that its response to the same stimulus (e.g., a microbial component) will be even dramatically different depending on its anatomical location.

An additional aspect of the inflammatory gene expression program that has been extensively analyzed in the last years is its kinetic complexity (Saccani et al. 2001). In fact, products of different inflammatory genes may have completely different cellular targets and may have to be released by migratory innate immune cells (such as dendritic cells [DCs]) in different tissues and at different times. Consider for instance a DC recruited at a peripheral site on microbial invasion and activated by microbial products. Among the first genes to be transcribed are those encoding chemokines (e.g., IL-8) that attract neutrophils to the inflammatory site to amplify the response and contain the invaders; then, genes encoding chemokine receptors enabling DC migration to lymph nodes (CCR7); and, eventually, genes relevant for Tand B-lymphocyte stimulation in the lymph node, such as CD80, CD86, and IL-6. In this regard, it is remarkable that in nonmigratory cells, such as fibroblasts, IL-6 is a rapidly induced gene, which indirectly implies the evolution of active mechanisms to delay its activation in DCs and macrophages.

At the level of individual genes, specific rules determining selectivity of induction in response to different inflammatory agonists as well as distinct kinetics of activation are increasingly being clarified. The recent availability of genomic approaches to analyze transcription and chromatin properties (Metzker 2010) has represented an enabling condition to move from single-gene analyses to global models describing the complexity of the response in an integrated manner. Moreover, with the refinement of technologies for screening based on RNA interference, it is now possible to evaluate the requirement for a large panel of transcriptional regulators in the inflammatory response. It is useful to classify inflammatory genes into primary and secondary response genes (PRGs and SRGs, respectively) based on their different requirements for new protein synthesis. PRG induction depends on preexisting signaling molecules and/or TFs, whereas SRG induction requires the de novo synthesis of signaling molecules and/or transcriptional regulators (such as interferon [IFN]- $\beta, \mathrm{C} / \mathrm{EBP} \delta$, and

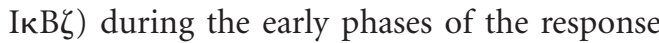
(Doyle et al. 2002; Yamamoto et al. 2004; Thomas et al. 2006; Litvak et al. 2009). Therefore, the expression of SRGs will be selectively impaired by protein synthesis inhibitors. For obvious reasons, PRGs tend to be induced faster than SRGs as a class, but individual exceptions have been described.

\section{THE INFLAMMATORY GENE EXPRESSION PROGRAM}

The gene expression cascade induced by inflammatory stimuli in mouse macrophages and DCs has been described with increasing resolution. The highest resolution studies have involved RNA-sequencing (RNA-seq) to examine either mature, polyadenylated mRNA or nascent transcripts (Rabani et al. 2011; Bhatt et al. 2012). RNA-seq of mRNA allows an examination of transcripts that may be available for translation into protein and considers the influences of regulation at the levels of transcription, RNA stability, and pre-mRNA processing. In contrast, nascent transcripts, which can be monitored by metabolic labeling, genome-wide nuclear runon (GRO-seq), or an examination of chromatin-associated transcripts, provides greater insight into transcriptional control independent of the influences of pre-mRNA processing and stability. An examination of nascent transcripts is especially valuable for defining the precise kinetics of transcriptional activation and 
inactivation of inducible genes. Comparisons of nascent transcript kinetics and mRNA kinetics in macrophages or DCs following lipopolysaccharide (LPS) stimulation have revealed that transcription is the primary mode of regulating inducible gene expression (Rabani et al. 2011; Bhatt et al. 2012). However, stability and premRNA processing play important roles in refining the expression pattern of many genes through the activities of miRNAs and other regulators of stability and processing (Hao and Baltimore 2009). Although transcription is the dominant regulator of inflammatory gene expression, transcription itself can be regulated at multiple levels, including the levels of transcription initiation, promoter escape, elongation, and termination. This topic is complicated and beyond the scope of this article. However, it is noteworthy that transcriptional regulation of a specific gene at any of these levels is ultimately dependent on the recognition of specific DNA sequences by sequence-specific TFs. Furthermore, even when gene induction is associated with release of a transcriptional pause or an increase in elongation efficiency, the frequency of transcription initiation also usually increases.

Despite the high-resolution, quantitative nature of recent RNA-seq studies of inflammatory gene induction, it is difficult to provide precise numbers of inducible genes, because such numbers are influenced by arbitrary decisions about transcript abundances and induction magnitudes required for the inclusion of genes in the set. One recent study reported 560 genes induced by more than fivefold at the nascent transcript level within $2 \mathrm{~h}$ of stimulation with lipid A (the active component of LPS) (Bhatt et al. 2012). However, more than 1000 genes were induced to a statistically significant extent during this same time period, with some genes induced by less than twofold and others induced by more than 1000-fold from their basal levels. These quantitative analyses further revealed that both the basal and maximal transcript levels for the set of induced genes spanned three orders of magnitude, with readily detected basal transcription of a large percentage of inducible genes. This extensive heterogeneity in basal and maximum transcription levels, as well as in fold-induction values, will ultimately need to be incorporated into both biological and mechanistic models of inflammatory gene expression. In addition, future studies will need to address the extensive heterogeneity in the gene expression cascade that has been documented in recent single-cell RNA-seq studies (RNA-seq) (Shalek et al. 2013). Despite the clear documentation of differential responses at a single-cell level within a population of phenotypically homogeneous cells, the biological and mechanistic significance of this heterogeneity remains unknown.

Notably, the hundreds of genes induced by LPS in macrophages and DCs can be divided into several defined clusters in which all genes within each cluster show similar temporal kinetics of transcription (Rabani et al. 2011; Bhatt et al. 2012). Given their similar kinetics, the genes within each cluster may be regulated by common sets of TFs. Consistent with this possibility, different transcription-factor-binding motifs were found to be overrepresented in the promoters of genes within different temporal clusters. Although these observations provide a path toward further dissection of the transcriptional program, each temporal cluster is undoubtedly heterogeneous, with different subsets of genes within each cluster regulated by different mechanisms.

\section{INTEGRATION OF SIGNALS AT THE CHROMATIN LEVEL}

\section{Transcription Factors Controlling the Inflammatory Response}

TFs activated in response to inflammatory stimuli belong to a few main families with distinct binding specificities (Fig. 1), including the nuclear factor of the $\kappa$ light chain enhancer of $\mathrm{B}$ cells (NF-кBs) (Hayden and Ghosh 2012), interferon regulatory factors (IRFs) (Tamura et al. 2008), signal transducers and activators of transcription (STAT) (Stark and Darnell 2012), and activator protein 1 (AP-1) (Wagner and Eferl 2005) families. Wiring of different receptors for microbial and endogenous danger signals 

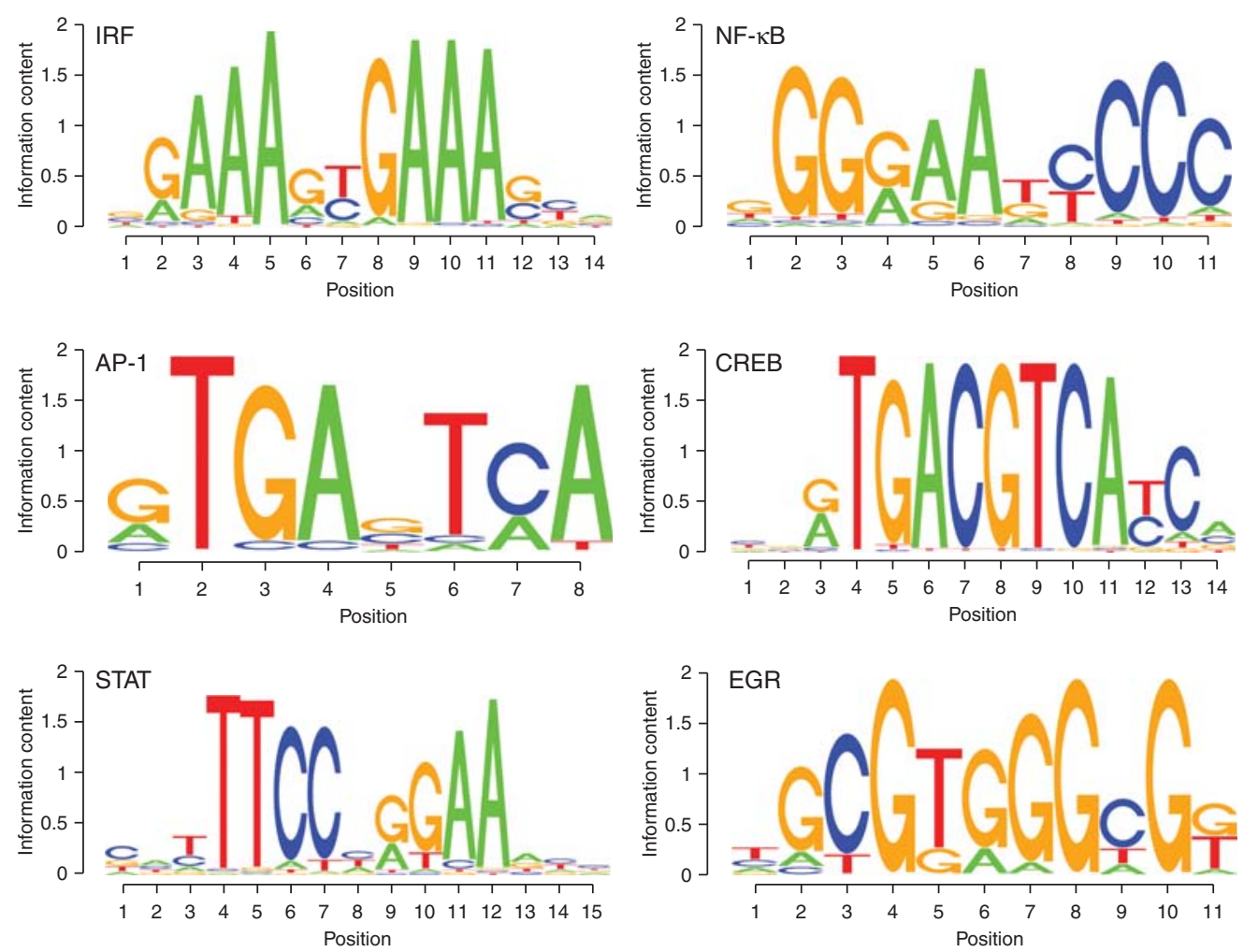

Figure 1. DNA recognition specificities of TFs that control inflammatory gene expression. Representative examples are shown.

to distinct signal transducers lays the groundwork for selective or preferential activation of subsets of these TFs. For instance, activation of IRF3 is selectively coupled to Toll-like receptor (TLR) 3 and TLR4 (Doyle et al. 2002; Toshchakov et al. 2002) and explains their ability to induce the IFN- $\beta$ gene and the downstream autocrine/paracrine IFN response, a property that is unique among TLRs. Conversely, cytokines acting primarily through the activation of STAT TFs such as IFN- $\gamma$, are in general unable to activate NF- $\kappa \mathrm{B}$ and AP-1, which are broadly responsive to a large panel of inflammatory agonists (ranging from LPS and most other microbial products to tumor necrosis factor $[\mathrm{TNF}]-\alpha$ ) (O'Shea and Plenge 2012).

The activity of these inflammatory TFs, however, is restrained and controlled by two main groups of factors: (1) nucleosomes, and (2) constitutively expressed TFs collectively de- fined here as master regulators that control the usage of both regulatory and coding genomic information in differentiated cells.

The Interplay between Nucleosomes and TFs in the Inflammatory Response

The great structural differences among the various classes of DNA-binding domains (Garvie and Wolberger 2001) explain why TFs have inherent differences in their ability to bind nucleosomal DNA. A broad class of TFs defined as pioneer factors (Zaret and Carroll 2011) and exemplified by the FoxA TFs, are operationally characterized by their ability to bind sites in a nucleosomal context and make them accessible. At the opposite side of the spectrum is TATA-binding protein, which is unable to bind the TATA sequence in a nucleosomal context (Imbalzano et al. 1994). TFs activated by in- 
flammatory agonists also appear to show a different ability to bind nucleosomal sites. STAT and IRF family TFs bind chromatin remodelers and, in this way, they may be able to promote access to otherwise occluded sequences (Huang et al. 2002; Liu et al. 2002; Cui et al. 2004). The scenario with NF- $\kappa \mathrm{B}$ is more controversial. From a structural point of view (Huxford et al. 1999), NF- $\mathrm{KB}$ is predicted to be unable to bind nucleosomal recognition sites (Natoli et al. 2005). However, an initial report suggested the surprising notion that the nucleosome does not even minimally impair NF- $\kappa$ B binding (Angelov et al. 2004). This apparent inconsistency was probably because of the experimental conditions used in these early experiments, which in fact relaxed octamer-DNA association and made underlying binding sites accessible to NF-кB (Lone et al. 2013). Taken together, data are consistent with the notion that the DNAbinding mode of NF- $\kappa \mathrm{B}$ makes it unable to contact sites associated with, and occluded by, nucleosomes.

Determinants of Nucleosome Positions and the Role of CpG Islands

Nucleosome positions are dictated by a combination of factors, including the underlying DNA sequence and the presence of trans-acting factors (mainly TFs) that compete with histones for binding the DNA and/or recruit chromatin remodeling activities that keep surrounding DNA accessible (Struhl and Segal 2013). In general, a moderate G/C content favors nucleosome assembly (Segal et al. 2006; Tillo and Hughes 2009) but the extreme guanine-cytosine content of some $\mathrm{CpG}$ islands is not compatible with efficient bending around the histone octamer and thus favors the formation of nucleosome-depleted areas (Ramirez-Carrozzi et al. 2009; Fenouil et al. 2012) that are rapidly accessible to stimulus-activated TFs as well as to the basal transcriptional machinery. The binding of ubiquitous TFs, such as Sp1, to many CpG islands is also likely to play a major role in the depletion of nucleosomes in these regions. Indeed, inflammatory genes containing a CpG island promoter are constitutively associated with
RNA polymerase (Pol II) (Hargreaves et al. 2009) have other features of active chromatin before stimulation, and often have higher basal transcriptional activity and are poised for further activation on stimulation (Ramirez-Carrozzi et al. 2009). Importantly, relaxed nucleosomal constraints to $\mathrm{TF}$ access to $\mathrm{CpG}$ island-containing genes favor promiscuous activation in response to multiple stimuli (Smale 2010).

Initial experiments on a limited set of inflammatory genes in macrophages indicated the possibility of a higher frequency of $\mathrm{CpG}$ islands at PRGs than at SRGs (Hargreaves et al. 2009; Ramirez-Carrozzi et al. 2009), suggesting that the presence of positioned nucleosomes at SRGs would impose the requirement for chromatin remodelers for gene activation. More recently, a genome-wide analysis of LPS-induced gene expression in macrophages revealed that, among PRGs, CpG-island promoters are most closely associated with transient induction, with more variable promoter architectures among PRGs that show sustained induction. A mechanistic explanation for the link between $\mathrm{CpG}$ islands and transient induction has not been obtained. Many SRG promoters have also been found to contain CpG islands (Bhatt et al. 2012). The CpG island-containing SRGs were not apparent in the earlier study because that study focused only on the most potently induced genes, which lack CpG-island promoters. Related to this observation, the most obvious distinction between genes containing and lacking CpG-island promoters is that genes lacking CpG islands, especially among SRGs, are generally induced by a larger magnitude (Bhatt et al. 2012). Therefore, although the presence or absence of a $\mathrm{CpG}$ island affects nucleosome occupancy and accessibility of promoters, it is not sufficient to distinguish between PRGs and SRGs. However, CpG island genes differ from non-CpG island genes because of the lower fold induction after stimulation. Mechanistically stable and strategically positioned nucleosomes that reduce basal transcriptional activity impose a tight regulation onto SRGs, and, thus, enable a high dynamic range compared with genes that are basally associated with the tran- 
scriptional machinery because of the presence of a CpG island in their promoters.

\section{GENOMIC REGULATORY ELEMENTS THAT CONTROL INFLAMMATORY GENE EXPRESSION}

\section{Identification of Genomic cis-Regulatory Elements}

The recent development of genomic approaches for the study of transcriptional regulation and, specifically, the combination of chromatin immunoprecipitation with multiparallel (or highthroughput) sequencing (ChIP-Seq) has enabled the identification of general principles of transcriptional control that were beyond the reach of single-gene studies (Barski et al. 2007).

The production of antibodies specific for different posttranslationally modified histones allowed the discovery that genomic regions with different functions are also marked with different sets of histone modifications (Bernstein et al. 2007). For instance, TSSs and adjacent regions of active genes or genes poised for activation are associated with trimethylation of histone $\mathrm{H} 3$ at lysine 4 (H3K4me3), whereas transcribed genic regions are associated with H3K36me2/3 and H3K79me2. A great advance in the field has been the characterization of a loose yet specific signature associated with distal transcriptional enhancers, whose identification has represented a major challenge for many years because of their variable distance from the target genes they regulate. The enhancer chromatin signature consists of high levels of monomethylated H3K4 (H3K4me1) (Heintzman et al. 2007) associated or not with histone acetylation (Creyghton et al. 2011; Rada-Iglesias et al. 2011). H3K4me1 is also detected at active or poised TSSs, but in those cases it is found on both sides of a central region marked by $\mathrm{H} 3 \mathrm{~K} 4 \mathrm{me} 3$, thus leading to an overall high $\mathrm{H} 3 \mathrm{~K} 4 \mathrm{me} 3 / \mathrm{mel}$ ratio. Conversely, this ratio is completely inverted at enhancers because of the higher H3K4mel level. Enhancers are also associated with transcriptional coregulators, such as the histone acetyltransferases (HAT) p300, CBP, and Tip60 (Heintzman et al. 2007;
Visel et al. 2009a), and, particularly when very active, they are subjected to RNA Pol II-mediated transcription (De Santa et al. 2010; Kim et al. 2010; Natoli and Andrau 2012).

\section{Enhancers Controlling Inflammatory Gene Expression}

Enhancer mapping in multiple cell types allowed determination of some basic principles of their usage in mammalian cells (Visel et al. $2009 b$ ). In general, an average of 40,000-50,000 regions bearing the chromatin signature of enhancers can be detected in any cell type, although such numbers vary depending on the statistical thresholds used in ChIP-Seq experiments. Although it is clear that the mere presence of a chromatin signature need not imply functionality, it is also clear that most or all enhancers that were previously characterized using genetic and functional approaches can be retrieved in ChIP-Seq experiments.

The initial characterization of enhancers involved in LPS-inducible gene expression in macrophages was based on the ability of stimulus-activated TFs, such as NF- $\mathrm{KB}$ and IRFs, to promote the recruitment of the p300 HAT (Ghisletti et al. 2010). LPS-inducible p300 recruitment unveiled thousands of enhancers and revealed their underlying sequence features. In addition to binding sites for LPS-activated TFs such as NF- $\mathrm{B}, \mathrm{AP}-1$, and IRF, these enhancers were almost invariably associated with binding sites for Pu.1, an Ets family protein that controls myeloid development and is expressed at very high levels in terminally differentiated macrophages (Scott et al. 1994; Nerlov and Graf 1998). $\mathrm{Pu} .1$ is constitutively bound to macrophage enhancers and is directly involved, together with partner TFs acting in different phases of macrophage development (Lichtinger et al. 2012), in determining both the deposition of $\mathrm{H} 3 \mathrm{~K} 4 \mathrm{me} 1$ and the displacement of nucleosomes to generate accessible DNA sequences (via TF-mediated recruitment of histone methyltransferases and ATP-dependent nucleosome remodeling complexes, respectively) (Fig. 2) (Ghisletti et al. 2010; Heinz et al. 2010). More generally, it is now clear that the specificity of the enhancer 


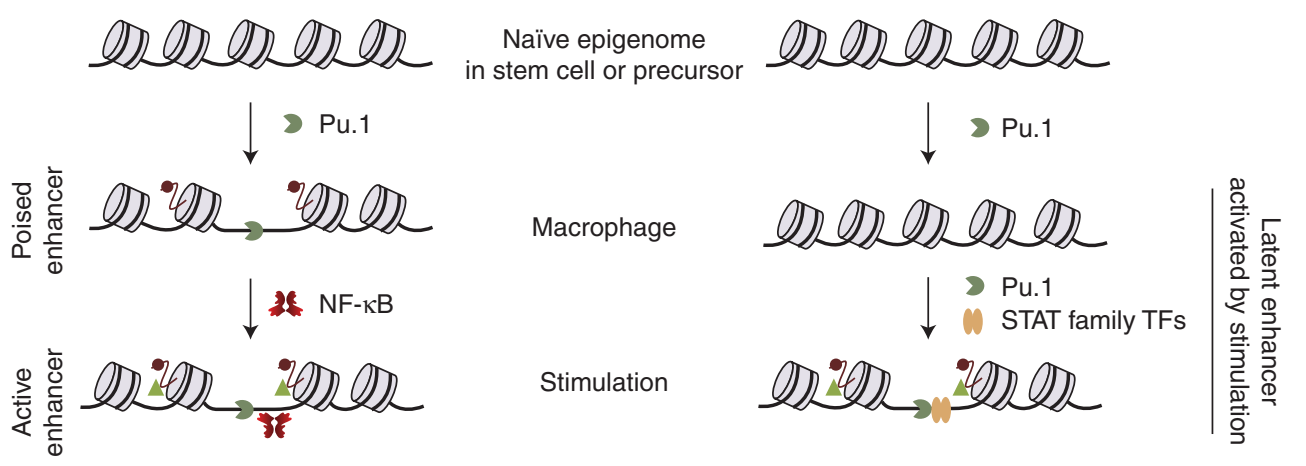

Figure 2. The relationship between nucleosomes, lineage-determining TFs, and TFs activated by inflammatory stimuli. (Left) A poised enhancer in which nucleosome depletion and deposition of H3K4me1 is induced by Pu.1 during differentiation. In response to stimulation TFs, such as NF- $\mathrm{B}$, are recruited to the nucleosome-depleted area maintained by Pu.1. (Right) Latent enhancers are not detectable in terminally differentiated cells until a stimulus is delivered that activates TFs (such as Stat TFs) collaborating with Pu.1 to reconfigure local chromatin.

landscape in different cell types is because of the direct activity of TFs involved in lineage specification and in maintenance of terminal differentiation (Natoli 2010). Indeed, at the basic molecular level, an essential function of these master regulators is to select the fraction of the enormous cis-regulatory repertoire available in mammalian genomes that will be used to regulate gene expression in that particular cell type. The functional role of H3K4me1 at enhancers is still unclear, although it may be involved in stabilizing the association of some HATs with enhancer nucleosomes (Jeong et al. 2011). Conversely, as discussed above, nucleosome displacement has the obvious consequence of making the underlying binding sites accessible to TFs (such as NF- $\kappa B$ ) that are unable to invade nucleosomal DNA. Therefore, the role of Pu.1 in macrophages as well as in other myeloid cells (Garber et al. 2012) is to make a broad and highly cell-type-specific repertoire of regulatory sequences available to other $\mathrm{TFs}$, including those activated in response to inflammatory stimuli (Fig. 2, left).

Clearly, TFs activated by inflammatory stimuli have little, if any, cell-type specificity, being similarly expressed and inducible in most cell types. Nevertheless, inflammatory gene expression is strictly cell-type specific both from a qualitative and a quantitative point of view.
For instance, IL12b is expressed only by macrophages and DCs, and TNF- $\alpha$ is produced at much higher levels by macrophages than by any other cell type in the body. The lack of specificity of inflammatory TFs is easily reconciled with the cell-type specificity of inflammatory gene expression when taking into consideration the uniqueness of the preexisting regulatory landscape generated by master regulators (such as Pu.1) that show restricted expression and divergent DNA-binding specificity.

\section{The Impact of Inflammatory Stimuli on the Enhancer Repertoire}

In general, active enhancers are associated with acetylated histones, whereas enhancers showing $\mathrm{H} 3 \mathrm{~K} 4 \mathrm{mel}$ in the absence of histone acetylation are assumed to be in a poised or in an actively repressed state. In macrophages, the vast majority of enhancers with constitutive H3K4me1 are in a poised state and only a small fraction $(<10 \%)$ of them can be inducibly acetylated in response to LPS (Ostuni et al. 2013). Different stimuli are able to activate distinct and only partially overlapping fractions of the large repertoire of poised enhancers. As discussed above, this inducible acetylation reflects recruitment to enhancers of TFs activated by stimulation and usually is reverted to almost baseline levels a 
few hours after activation. A different situation occurs at a smaller subset of enhancers, representing $\sim 15 \%$ of the enhancers activated by individual stimuli; at these enhancers, histone $\mathrm{H} 3 \mathrm{~K} 4 \mathrm{mel}$ and other enhancer marks are not identifiable in unstimulated cells by ChIPSeq or related approaches. These latent enhancers (Fig. 2, right) (Ostuni et al. 2013) acquire $\mathrm{H} 3 \mathrm{~K} 4 \mathrm{mel}$ and H3K27Ac and undergo an increase in accessibility over several hours after stimulation, thus reflecting a slow process of chromatin reorganization that depends on the functional cooperation between stimulus-activated TFs (such as Stat1 and Stat6 induced in response to IFN- $\gamma$ and IL-4, respectively) and $\mathrm{Pu}$.1. The repertoire of latent enhancers is very specific to the stimulus used, with very little overlap between unrelated stimuli. Importantly, after stimulation has ceased, while acetylation and binding of Pu.1 and stimulus-activated TFs are rapidly reversed, $\mathrm{H} 3 \mathrm{~K} 4 \mathrm{me} 1$ persists for days and this correlates with a faster and higher acetylation if macrophages are restimulated. The priming effect on reacetylation may relate to the ability of $\mathrm{H} 3 \mathrm{~K} 4 \mathrm{me} 1$ to promote and stabilize the recruitment of specific HATs (such as Tip60) to enhancers (Jeong et al. 2011). Irrespective of the underlying mechanism, the persistence of histone marks at latent enhancers after stimulus withdrawal suggests the existence of a sort of short-term memory of the initial stimulation and may help explain the conditioning effect of primary stimulation on the response of macrophages to a subsequent stimulus.

\section{CONCLUDING REMARKS}

Recent technological advances have enabled a great and rapid expansion of the knowledge of mechanisms controlling transcriptional responses to inflammatory stimuli. Availability of genome-scale expression data will allow a more and more refined classification of inflammatory genes based on their properties, such as selective induction in response to specific agonists, cell-type-restricted expression and kinetics of activation. At the same time, unraveling transcriptional and chromatin-regulated mechanisms involved in the activation and fine-tuning of inflammatory gene transcription will allow linking regulatory elements and combinations of TFs acting on them to distinct groups of genes, thus providing a systems-level and mechanism-based understanding of the molecular basis of transcriptional control of inflammation. It would be tempting to hypothesize that in the future such knowledge may allow precisely predicting the impact of chemicals and drugs that selectively act on specific signal-transduction pathways (e.g., c-Jun amino-terminal kinase [JNK] inhibitors), TFs (e.g., glucocorticoids), and chromatin regulators (e.g., bromodomain and extraterminal [BET] inhibitors) (Nicodeme et al. 2010).

\section{ACKNOWLEDGMENTS}

Research in the S.T.S. group is supported by the U.S. National Institutes of Health. Research on this topic in the G.N. group is mainly supported by the European Research Council Grant NORM (Nuclear Organization of Macrophages).

\section{REFERENCES}

Angelov D, Lenouvel F, Hans F, Muller CW, Bouvet P, Bednar J, Moudrianakis EN, Cadet J, Dimitrov S. 2004. The histone octamer is invisible when NF- $\mathrm{KB}$ binds to the nucleosome. J Biol Chem 279: 42374-42382.

Barski A, Cuddapah S, Cui K, Roh TY, Schones DE, Wang Z, Wei G, Chepelev I, Zhao K. 2007. High-resolution profiling of histone methylations in the human genome. Cell 129: $823-837$.

Bernstein BE, Meissner A, Lander ES. 2007. The mammalian epigenome. Cell 128: 669-681.

Bhatt DM, Pandya-Jones A, Tong AJ, Barozzi I, Lissner MM, Natoli G, Black DL, Smale ST. 2012. Transcript dynamics of proinflammatory genes revealed by sequence analysis of subcellular RNA fractions. Cell 150: 279-290.

Creyghton MP, Cheng AW, Welstead GG, Kooistra T, Carey BW, Steine EJ, Hanna J, Lodato MA, Frampton GM Sharp PA, et al. 2011. Histone H3K27ac separates active from poised enhancers and predicts developmental state. Proc Natl Acad Sci 107: 21931-21936.

Cui K, Tailor P, Liu H, Chen X, Ozato K, Zhao K. 2004. The chromatin-remodeling BAF complex mediates cellular antiviral activities by promoter priming. Mol Cell Biol 24: 4476-4486.

De Santa F, Barozzi I, Mietton F, Ghisletti S, Polletti S, Tusi BK, Muller H, Ragoussis J, Wei CL, Natoli G. 2010. A large fraction of extragenic RNA pol II transcription sites overlap enhancers. PLoS Biol 8: e1000384. 
Doyle S, Vaidya S, O'Connell R, Dadgostar H, Dempsey P, Wu T, Rao G, Sun R, Haberland M, Modlin R, et al. 2002. IRF3 mediates a TLR3/TLR4-specific antiviral gene program. Immunity 17: 251-263.

Fenouil R, Cauchy P, Koch F, Descostes N, Cabeza J, Innocenti Cn, Ferrier P, Spicuglia S, Gut M, Gut I, et al. 2012. CpG islands and GC content dictate nucleosome depletion in a transcription-independent manner at mammalian promoters. Genome Res 22: 2399-2408.

Garber M, Yosef N, Goren A, Raychowdhury R, Thielke A, Guttman M, Robinson J, Minie B, Chevrier N, Itzhaki Z, et al. 2012. A high-throughput chromatin immunoprecipitation approach reveals principles of dynamic gene regulation in mammals. Mol Cell 47: 810-822.

Garvie C, Wolberger C. 2001. Recognition of specific DNA sequences. Mol Cell 8: 937-946.

Ghisletti S, Barozzi I, Mietton F, Polletti S, De Santa F, Venturini E, Gregory L, Lonie L, Chew A, Wei CL, et al. 2010 Identification and characterization of enhancers controlling the inflammatory gene expression program in macrophages. Immunity 32: 317-328.

Hao S, Baltimore D. 2009. The stability of mRNA influences the temporal order of the induction of genes encoding inflammatory molecules. Nat Immunol 10: 281-288.

Hargreaves DC, Horng T, Medzhitov R. 2009. Control of inducible gene expression by signal-dependent transcriptional elongation. Cell 138: 129-145.

Hayden M, Ghosh S. 2012. NF-кB, the first quarter-century: Remarkable progress and outstanding questions. Genes Dev 26: 203-234.

Heintzman N, Stuart R, Hon G, Fu Y, Ching C, Hawkins R, Barrera L, Van Calcar S, Qu C, Ching K, et al. 2007. Distinct and predictive chromatin signatures of transcriptional promoters and enhancers in the human genome. Nat Genet 39: 311-318.

Heinz S, Benner C, Spann N, Bertolino E, Lin YC, Laslo P, Cheng JX, Murre C, Singh H, Glass CK. 2010. Simple combinations of lineage-determining transcription factors prime cis-regulatory elements required for macrophage and B cell identities. Mol Cell 38: 576-589.

Huang M, Qian F, Hu Y, Ang C, Li Z, Wen Z. 2002. Chromatin-remodelling factor BRG1 selectively activates a subset of interferon- $\alpha$-inducible genes. Nat Cell Biol 4 774-781.

Huxford T, Malek S, Ghosh G. 1999. Structure and mechanism in NF-кB/IкB signaling. Cold Spring Harb Symp Quant Biol 64: 533-540.

Imbalzano AN, Kwon H, Green MR, Kingston RE. 1994. Facilitated binding of TATA-binding protein to nucleosomal DNA. Nature 370: 481-485.

Jeong KW, Kim K, Situ AJ, Ulmer TS, An W, Stallcup MR. 2011. Recognition of enhancer element-specific histone methylation by TIP60 in transcriptional activation. Nat Struct Mol Biol 18: 1358-1365.

Kim T-K, Hemberg M, Gray J, Costa A, Bear D, Wu J, Harmin D, Laptewicz M, Barbara-Haley K, Kuersten S, et al. 2010. Widespread transcription at neuronal activity-regulated enhancers. Nature 465: 182-187.

Lichtinger M, Ingram R, Hannah R, Moller D, Clarke D, Assi S, Lie-A-Ling M, Noailles L, Vijayabaskar M, Wu M, et al.
2012. RUNX1 reshapes the epigenetic landscape at the onset of haematopoiesis. EMBO J 31: 4318-4333.

Litvak V, Ramsey S, Rust A, Zak D, Kennedy K, Lampano A, Nykter M, Shmulevich I, Aderem A. 2009. Function of C/ EBP $\delta$ in a regulatory circuit that discriminates between transient and persistent TLR4-induced signals. Nat Immunol 10: 437-443.

Liu H, Kang H, Liu R, Chen X, Zhao K. 2002. Maximal induction of a subset of interferon target genes requires the chromatin-remodeling activity of the BAF complex. Mol Cell Biol 22: 6471-6479.

Lone IN, Shukla MS, Charles Richard JL, Peshev ZY, Dimitrov S, Angelov D. 2013. Binding of NF- $\kappa B$ to nucleosomes: Effect of translational positioning, nucleosome remodeling and linker histone H1. PLoS Genet 9: e1003830.

Medzhitov R, Horng T. 2009. Transcriptional control of the inflammatory response. Nat Rev Immunol 9: 692-703.

Metzker M. 2010. Sequencing technologies-The next generation. Nat Rev Genet 11: 31-46.

Natoli G. 2010. Maintaining cell identity through global control of genomic organization. Immunity 33: 12-24.

Natoli G, Andrau JC. 2012. Noncoding transcription at enhancers: General principles and functional models. Annu Rev Genet 46: 1-19.

Natoli G, Saccani S, Bosisio D, Marazzi I. 2005. Interactions of NF- $\kappa \mathrm{B}$ with chromatin: The art of being at the right place at the right time. Nat Immunol 6: 439-445.

Nerlov C, Graf T. 1998. PU.1 induces myeloid lineage commitment in multipotent hematopoietic progenitors. Genes Dev 12: 2403-2412.

Nicodeme E, Jeffrey KL, Schaefer U, Beinke S, Dewell S, Chung CW, Chandwani R, Marazzi I, Wilson P, Coste $\mathrm{H}$, et al. 2010. Suppression of inflammation by a synthetic histone mimic. Nature 468: 1119-1123.

O'Shea J, Plenge R. 2012. JAK and STAT signaling molecules in immunoregulation and immune-mediated disease. Immunity 36: 542-550.

Ostuni R, Piccolo V, Barozzi I, Polletti S, Termanini A, Bonifacio S, Curina A, Prosperini E, Ghisletti S, Natoli G. 2013. Latent enhancers activated by stimulation in differentiated cells. Cell 152: 157-171.

Rabani M, Levin JZ, Fan L, Adiconis X, Raychowdhury R, Garber M, Gnirke A, Nusbaum C, Hacohen N, Friedman N, et al. 2011. Metabolic labeling of RNA uncovers principles of RNA production and degradation dynamics in mammalian cells. Nat Biotechnol 29: 436-442.

Rada-Iglesias A, Bajpai R, Swigut T, Brugmann SA, Flynn RA, Wysocka J. 2011. A unique chromatin signature uncovers early developmental enhancers in humans. Nature 470: 279-283.

Ramirez-Carrozzi VR, Braas D, Bhatt DM, Cheng CS, Hong C, Doty KR, Black JC, Hoffmann A, Carey M, Smale ST. 2009. A unifying model for the selective regulation of inducible transcription by $\mathrm{CpG}$ islands and nucleosome remodeling. Cell 138: 114-128.

Saccani S, Pantano S, Natoli G. 2001. Two waves of nuclear factor $\kappa \mathrm{B}$ recruitment to target promoters. J Exp Med 193: $1351-1359$.

Scott EW, Simon MC, Anastasi J, Singh H. 1994. Requirement of transcription factor PU.1 in the development of 
S.T. Smale and G. Natoli

multiple hematopoietic lineages. Science 265: $1573-$ 1577.

Segal E, Fondufe-Mittendorf Y, Chen L, Thåström A, Field Y, Moore I, Wang J-PZ, Widom J. 2006. A genomic code for nucleosome positioning. Nature 442: 772-778.

Shalek AK, Satija R, Adiconis X, Gertner RS, Gaublomme JT, Raychowdhury R, Schwartz S, Yosef N, Malboeuf C, Lu D, et al. 2013. Single-cell transcriptomics reveals bimodality in expression and splicing in immune cells. Nature 498: 236-240.

Smale ST. 2010. Selective transcription in response to an inflammatory stimulus. Cell 140: 833-844.

Stark G, Darnell J. 2012. The JAK-STAT pathway at twenty. Immunity 36: 503-514.

Struhl K, Segal E. 2013. Determinants of nucleosome positioning. Nat Struct Mol Biol 20: 267-273.

Tamura T, Yanai H, Savitsky D, Taniguchi T. 2008. The IRF family transcription factors in immunity and oncogenesis. Annu Rev Immunol 26: 535-584.

Thomas KE, Galligan CL, Newman RD, Fish EN, Vogel SN. 2006. Contribution of interferon- $\beta$ to the murine macrophage response to the Toll-like receptor 4 agonist, lipopolysaccharide. J Biol Chem 281: 31119-31130.
Tillo D, Hughes T. 2009. G+C content dominates intrinsic nucleosome occupancy. BMC Bioinformatics 10: 442.

Toshchakov V, Jones B, Perera P-Y, Thomas K, Cody M, Zhang S, Williams B, Major J, Hamilton T, Fenton M, et al. 2002. TLR4, but not TLR2, mediates IFN- $\beta$-induced STAT $1 \alpha / \beta$-dependent gene expression in macrophages. Nat Immunol 3: 392-398.

Visel A, Blow MJ, Li Z, Zhang T, Akiyama JA, Holt A, Plajzer-Frick I, Shoukry M, Wright C, Chen F, et al. 2009a. ChIP-seq accurately predicts tissue-specific activity of enhancers. Nature 457: 854-858.

Visel A, Rubin EM, Pennacchio LA. 2009b. Genomic views of distant-acting enhancers. Nature 461: 199-205.

Wagner E, Eferl R. 2005. Fos/AP-1 proteins in bone and the immune system. Immunol Rev 208: 126-140.

Yamamoto M, Yamazaki S, Uematsu S, Sato S, Hemmi H, Hoshino K, Kaisho T, Kuwata H, Takeuchi O, Takeshige $\mathrm{K}$, et al. 2004. Regulation of Toll/IL-1-receptor-mediated gene expression by the inducible nuclear protein ІкВ $\zeta$. Nature 430: 218-222.

Zaret KS, Carroll JS. 2011. Pioneer transcription factors: Establishing competence for gene expression. Genes Dev 25: 2227-2241. 


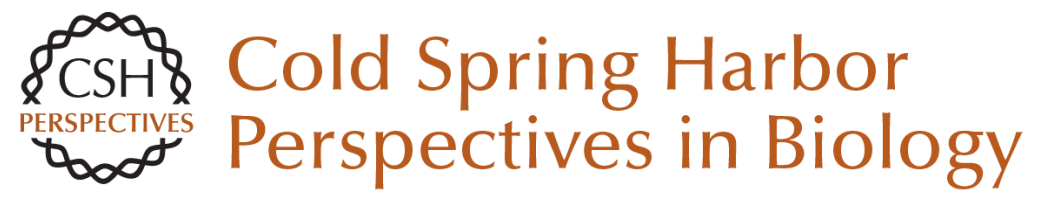

\section{Transcriptional Control of Inflammatory Responses}

Stephen T. Smale and Gioacchino Natoli

Cold Spring Harb Perspect Biol 2014; doi: 10.1101/cshperspect.a016261 originally published online September 11, 2014

Subject Collection Innate Immunity and Inflammation

Group 2 Innate Lymphoid Cells in Health and Disease

Brian S. Kim and David Artis

Inflammation and the Blood Microvascular

System

Jordan S. Pober and William C. Sessa

Sinusoidal Immunity: Macrophages at the

Lymphohematopoietic Interface

Siamon Gordon, Annette Plüddemann and

Subhankar Mukhopadhyay

Allergic Inflammation--Innately Homeostatic Laurence E. Cheng and Richard M. Locksley

Approaching the Next Revolution? Evolutionary Integration of Neural and Immune Pathogen

Sensing and Response

Kevin J. Tracey

Inflammasomes

Marcel R. de Zoete, Noah W. Palm, Shu Zhu, et al.

IL-6 in Inflammation, Immunity, and Disease

Toshio Tanaka, Masashi Narazaki and Tadamitsu Kishimoto
The Chemokine System in Innate Immunity Caroline L. Sokol and Andrew D. Luster

Microbial Sensing by Toll-Like Receptors and Intracellular Nucleic Acid Sensors Surya Pandey, Taro Kawai and Shizuo Akira

Tumor Necrosis Factor Superfamily in Innate Immunity and Inflammation John Sedý, Vasileios Bekiaris and Carl F. Ware

\section{Emerging Principles Governing Signal}

Transduction by Pattern-Recognition Receptors Jonathan C. Kagan and Gregory M. Barton

Lipid Mediators in the Resolution of Inflammation Charles N. Serhan, Nan Chiang, Jesmond Dalli, et al.

Transcriptional Control of Inflammatory

Responses

Stephen T. Smale and Gioacchino Natoli

DNA Degradation and Its Defects

Kohki Kawane, Kou Motani and Shigekazu Nagata

For additional articles in this collection, see http://cshperspectives.cshlp.org/cgi/collection/

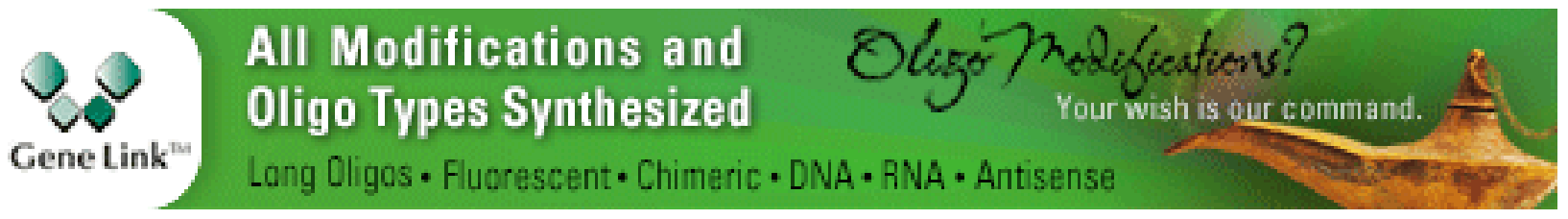

Copyright (C 2014 Cold Spring Harbor Laboratory Press; all rights reserved 